\title{
Dictionnaire de Stendhal, publié sous la direction d'Yves Ansel, Philippe Berther et Michael Nerlich
}

\section{Valentina Ponzetto}

\section{Q OpenEdition}

12 Journals

\section{Edizione digitale}

URL: http://journals.openedition.org/studifrancesi/36342

DOI: 10.4000/studifrancesi.36342

ISSN: 2421-5856

\section{Editore}

Rosenberg \& Sellier

\section{Edizione cartacea}

Data di pubblicazione: 1 juillet 2005

Paginazione: 179

ISSN: 0039-2944

\section{Notizia bibliografica digitale}

Valentina Ponzetto, «Dictionnaire de Stendhal, publié sous la direction d'Yves Ansel, Philippe Berther et Michael Nerlich», Studi Francesi [Online], 145 (XLIX | I) | 2005, online dal 30 novembre 2015, consultato il 18 avril 2021. URL: http://journals.openedition.org/studifrancesi/36342 ; DOI: https://doi.org/ 10.4000/studifrancesi.36342

\section{Questo documento è stato generato automaticamente il 18 avril 2021.}

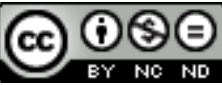

Studi Francesi è distribuita con Licenza Creative Commons Attribuzione - Non commerciale - Non opere derivate 4.0 Internazionale. 


\title{
Dictionnaire de Stendhal, publié sous la direction d'Yves Ansel, Philippe Berther et Michael Nerlich
}

\author{
Valentina Ponzetto
}

\section{NOTIZIA}

Dictionnaire de Stendhal, publié sous la direction d'YVES ANSEL, PHILIPPE BERTHER et MICHAEL NERLICH, Paris, Honoré Champion, 2003, pp. 776.

1 Dopo Rousseau, Diderot e Voltaire, Champion dedica ora uno dei suoi imponenti dizionari a Stendhal, nell'intento di offrire a tutti, profani e professori, amatori ed eruditi, «toutes les [bonnes] entrées en Stendhalie». Frutto del lavoro di un'équipe internazionale di una quarantina di collaboratori molto differenti per formazione e orientamento, che propongono un ampio ventaglio di letture - formaliste, tematiche, genetiche, psicanalitiche, storiche, politiche, sociologiche, simboliche, ecc. - questo dizionario si presenta, dichiaratamente, come un'opera destinata alla consultazione. Proprio per questo ogni voce, perfettamente indipendente, si chiude con una bibliografia propria, spesso affiancata da un rimando alle parole-chiave più strettamente correlate per un'eventuale approfondimento.

2 Una prima tipologia di voci è dedicata all'uomo Henri Beyle e ai più vari aspetti della sua biografia. Si potranno trovare così le più scontate informazioni sulla sua famiglia, gli amici, le amanti, i corrispondenti, i libri letti, i viaggi, le città che hanno segnato la sua vita, ma anche piccole e sfiziose curiosità anedottiche, come la sua passione per gli spinaci, o il dettaglio degli occhiali dalle lenti verdi indossati per inseguire in incognito Métilde Dembowski a Volterra.

3 Vi sono poi, ovviamente, le opere di Stendhal, catalogate tutte, imparzialmente, secondo gli stessi criteri, dai celeberrimi La Chartreuse de Parme e Le Rouge et le Noir, alle opere autobiografiche, ai piccoli saggi marginali, alle opere incompiute, ai semplici 
abbozzi. Per ogni opus sono riportate le date di composizione e pubblicazione, alcune notizie sul manoscritto, essenzialmente collocazione e descrizione, una breve presentazione del contenuto, seguita da un commento, e l'indicazione delle edizioni di riferimento e della bibliografia essenziale. Accanto alle esigenze imposte dal carattere enciclopedico del dizionario, influiscono su questa scelta, come è sottolineato dall'introduzione, anche i più recenti orientamenti della critica, volti a riscoprire in Stendhal, oltre all'autore dei più grandi romanzi, anche il poligrafo, il cronachista, l'eccellente giornalista, senza tralasciare le illuminanti scoperte che gli studi di genetica testuale hanno saputo trarre dall'esplorazione delle opere incompiute.

Un terzo tipo di voci riguarda i temi ricorrenti e privilegiati di questo corpus stendhaliano allargato, seguiti attraverso la vita e l'opera del romanziere sulla scorta di un'accurata scelta di citazioni. Si tratta in parte, naturalmente, di temi assai generali e comuni a molli altri scrittori, quali ambizione, amore, denaro, donne, morale, politica, società, in parte di questioni più specifiche e intimamente stendhaliane, quali babilanisme, chicane, égotisme, jansénisme, opéra, prison.

5 Da questa seconda famiglia di temi il passo è breve verso l'ultima e più sottile delle categorie proposte dagli estensori del dizionario: quella del lessico distintivo di Stendhal, delle parole ed espressioni che portano indelebilmente il suo marchio o che assumono sotto la sua penna risonanze particolari. Come non ricordare, per esempio, che a lui si devono l'introduzione o la voga nella lingua francese di cristallisation, égotisme, fiasco, "happy few", romanticisme. Al di là dei neologismi, di cui Standhal fu grande amatore e inventore, si potrebbe allungare all'infinito la lista delle voci e delle formule immancabili, da «Logique», o «etc. etc.», ai celeberrimi «écrire comme le code civil» o «un roman: c'est un miroir», e ancora énergie, o ironie, «notre héros» o "petits faits vrais», platitude o vanité, bruit, chausse, chute, étiolé, odieux, altrettante espressionifeticcio che portano con sé tutto un immaginario e una visione del mondo firmata, per sempre, Stendhal. 